\title{
Estudos de Morbidade: Usos e Limites.*
}

Maria Lúcia Lebrão**

Nas apresentações das Prof. Luana e Nilce pode ser visto um pouco das dificuldades existentes nos estudos de morbidade, especificamente nos inquéritos domiciliares e na odontologia. No entanto, apesar dessas dificuldades, as estatísticas de morbidade têm hoje uma importância cada vez maior pois elas são mais reveladoras que as de mortalidade, uma vez que estas mostram um quadro de saúde como ela foi, enquanto que para se perceber a saúde como ela é, é necessário utilizar as estatísticas de morbidade. Elas representam as condições de saúde de uma população com muito mais sensibilidade que as taxas de óbitos.

Em vista da alta perda econômica e da perturbação social causada pela doença e pelo custo do cuidado médico, é necessário que se tenha informações exatas para planejar medidas de prevenção sobre uma base adequada. Assim, a quantidade e a duração da doença, e não somente a mortalidade que produz, são importantes.

A utilidade das estatísticas de morbidade está em geral ligada a essa informação, detalhada nos seguintes pontos:

a) quantas pessoas sofrem de determinadas doenças, com que freqüência e por quanto tempo;

b) que demanda exercem essas doenças sobre os recursos médicos de saúde pública e que perda financeira causam;

c) qual a letalidade das diferentes doenças;

d) em que extensão as pessoas estão prevenidas contra essas doenças ao efetuar suas atividades normais;

e) em que extensão as doenças estão concentradas em grupos específicos da população, por exemplo, de acordo com a idade, sexo, grupo étnico, ocupação ou lugar de residência;

* O conteúdo desta apresentação faz parte do livro "Estudos de Morbidade", a ser lançado futuramente.

** Professora Associada do Departamento de Epidemiologia da Faculdade de Saúde Pública da USP. 
f) qual a variação desses fatores no tempo;

g) qual o efeito da atenção médica e dos serviços de saúde pública sobre o controle da incidência da doença.

Apesar de vários organismos colherem algum tipo de estatística de morbidade, sempre vai existir uma lacuna no conhecimento do estado de saúde geral das populações. É bastante conhecido o exemplo de Swaroopdo conhecimento da situação de saúde de uma população, onde ele mostra a existência de um grande vazio de informações, ao mesmo tempo em que há duplicidade de informações.

Qualquer estudo de morbidade estará incompleto se utilizar registros de uma só fonte. Porém, as fontes comumente consideradas para os estudos de morbidade, citadas abaixo têm, todas, as suas vantagens e desvantagens:

1. Notificação compulsória de doenças;

2. Estatísticas hospitalares;

3. Estatísticas de serviços de assistência ambulatorial;

4. Registros médicos de indústrias e escolas;

5. Registros especiais de doenças;

6. Registros de óbitos;

7. Inquéritos domiciliares;

8. Outras fontes, tais como: registros de médicos particulares, Seguro Social e de Saúde, Censo populacional.

Nos países não desenvolvidos, e mesmo naqueles economicamente avançados onde as doenças infecciosas só contribuem em pequena proporção na morbidade, o sistema de notificação compulsória pode desempenhar um papel de vital importância, monitorando a disseminação de uma epidemia e facilitando algumas providências tais como quarentena e vacinação.

Ainda que a finalidade principal da notificação não seja a estatística, os organismos oficiais de saúde costumam recorrer a ela como fonte de dados. Porém, mesmo que ela seja uma fonte valiosa, o seu aproveitamento é limitado por certos inconvenientes e, em particular, pelo fato de que ela se restringe a um número limitado de doenças. Mas, essa é uma contingência desse tipo de vigilância, dadas as dificuldades de operacionalização dessas atividades. No entanto, algumas críticas a esse sistema são baseadas em uma concepção errônea a respeito dos seus propósitos. O principal propósito da notificação é dar subsídios para o reforço da intervenção da saúde pública em doenças específicas.

As críticas a esses sistemas passivos, ocorrem por conta da:

\# sub-notificação de doenças,

\# falta de representatividade dos casos que são notificados,

\# falta de oportunidade no registro,

\# falta de sensibilidade e/ou especificidade e, \# diagnósticos incorretos pelos médicos. 
Casos contados a partir de um sistema passivo de notificação não podem, de forma alguma, dar uma noção completa da ocorrência da doença e não são, provavelmente, uma amostra estatisticamente representativa. Felizmente não é essencial obter contagens completas para empreender esforços efetivos no controle dessas doenças.

No entanto, o fato de elas serem incompletas, não implica que esses dados de vigilância não possam servir a seus propósitos. Mudanças temporais no número de casos notificados refletem adequadamente as tendências e, mesmo registros incompletos de doenças podem ser analisados para detectar surtos ou para avaliar o impacto de um programa intervencional. Mudanças espaciais e temporais podem usualmente ser detectadas, a menos que o mecanismo básico de notificação varie imprevisivelmente. Exemplo desse fato é o aumento da notificação de hepatite viral observado por Escrivão Jr. , após a implantação da norma 7/71 no Estado de São Paulo, que reformulava a sistemática da coleta de dados referentes à notificação compulsória. Em algumas regionais o coeficiente de incidência dessa doença passou de 5 para 100 por 100.000 habitantes. Outro exemplo a ser lembrado é o que diz respeito à ampliação, recente, da notificação do sarampo, incluindo os não hospitalizados no Estado de São Paulo, que elevou o número de casos notificados.

Considera-se que epidemias, assim como tendências gerais temporais e geográficas podem ser determinadas desde que as proporções de casos detectados permaneça consistente ao longo do tempo e das áreas geográficas.

No que pesem os inconvenientes, no entanto, é evidente que as notificações desempenham um papel importante uma vez que as suas flutuações proporcionam indicações muito úteis sobre a iminência de surtos epidêmicos e, pelo fato de serem coletadas continuamente, permitem a análise de rotina dos dados por tempo, lugar e pessoa, podendo, assim, detectar padrões incomuns da doença e deflagrar investigação epidêmica em tempo.

Embora sejam muitas as restrições às estatísticas hospitalares no campo da epidemiologia, deve-se lembrar que ela é o único registro sistemático de informações de morbidade. Os dados hospitalares têm a vantagem de serem relativamente seguros, uma vez que dizem respeito a pacientes que, com raras exceções, foram vistos por profissionais médicos.

Costuma-se dizer que as estatísticas hospitalares são seletivas pois somente fornecem informações relativas às doenças graves o bastante para exigirem hospitalização e, parciais porque apenas uma parcela delas chega ao hospital, pelas várias razões que levam um doente a não ter uma internação: podem não ser considerados necessitados, estão muito distantes dos hospitais, são ignorantes da existência dos recursos, não têm condições financeiras, não obtêm vagas, têm medo ou, ainda, são excluídos por alguma razão administrativa.

Mesmo em relação a uma condição que pode ocorrer somente uma vez na vida e que, sempre requer hospitalização, tal como a apendicite aguda tratada 
por remoção cirúrgica, não há como se ter domínio dessa informação, pois um paciente pode ter mais de uma estada no hospital se ele tiver complicações que requeiram readmissão e, o mesmo diagnóstico de saída "apendicite aguda", pode ser registrado quando o paciente deixa o hospital depois da readmissão. Se a readmissão é em hospital diferente, não há meio de saber se os números registrados nos resumos estatísticos de diferentes hospitais dizem respeito ao mesmo paciente. Múltiplas internações de um paciente, no mesmo ou em diferentes hospitais, ocorrem freqüentemente para condições tais como diabetes instável e doença pulmonar obstrutiva crônica. Por outro lado, outras condições, tais como úlcera péptica e doença coronariana do coração, podem não levar ao hospital ou porque a doença nem sempre é grave o bastante para requerer internação ou porque o paciente morre antes que a admissão seja possível.

Nasce daí a impossibilidade de se calcular coeficientes, uma vez que não só não se conhece o denominador da fração, pois a população de risco quase nunca é circunscrita, como no numerador ter-se-á doenças e, não, doentes.

Assim, é preciso ter em mente que essas informações nunca serão representativas da morbidade da coletividade, como de resto também não o são todas as informações provenientes da demanda aos serviços de saúde. É possível que se esteja medindo mais a oferta de recursos do que realmente a necessidade da população. Locais onde a oferta for menor do que o necessário, a demanda será pequena, pela própria imposição da falta de recursos. Por outro lado, a existência de grandes centros hospitalares e especializados, tenderá a atrair a demanda.

No entanto, o aproveitamento total das estatísticas hospitalares poderia ser feito na medida em que se pudesse dispor de sistemas de "linkage" entre as várias internações em hospitais diferentes ou mesmo entre essa fonte e outras fontes de morbidade ou mesmo de óbito. Infelizmente, ainda hoje, esses recursos estão restritos a tentativas localizadas.

No conjunto das fontes que fazem o grande mapa da morbidade de uma localidade, as informações provenientes dos atendimentos ambulatoriais devem ter lugar certo, uma vez que grande parte da morbidade dita "leve" estará presente aí, sem que seja necessário lançar mão de processos caros e difíceis como um inquérito domiciliar, por exemplo. Uma grande parte das causas de morbidade mais freqüentes nas populações tem uma letalidade relativamente baixa e outras não aparecem representadas na mortalidade a não ser indiretamente, como acontece com as doenças mentais.

Essa fonte passa a ter importância cada vez maior pois, progressivamente, o atendimento ambulatorial vem se tornando o fim na assistência médica, pelo alto custo da hospitalização e pelas mudanças na tecnologia, que permitem que muitas doenças que antigamente eram de tratamento hospitalar passassem a ser resolvidas em nível de ambulatório. 
No entanto, os registros de atendimento ambulatorial, como fonte de dados têm muitas limitações que resultam da variedade de arranjos e pessoal envolvido e das características de alto volume/baixo custo/trabalho intensivo das atividades, sendo a guarda dos prontuários, freqüentemente, mantida em um padrão muito baixo.

$\mathrm{O}$ primeiro ponto a ser levantado advém do fato de ser essa uma informação proveniente da demanda e, assim, é possível que se esteja medindo mais a oferta de recursos do que realmente a necessidade da população, da mesma forma que nas estatísticas hospitalares.

É preciso não esquecer, ainda, que, mesmo que se tenha uma oferta adequada de serviços, sempre se estará lidando com voluntários, que não necessariamente procurarão os serviços quando doentes.

Outro ponto importante, e que é um requisito essencial, o denominador das taxas, é desconhecido porque o provedor dos cuidados - clínica ou consultório médico - raramente serve a uma população definida. Faz exceção a Inglaterra, onde os médicos generalistas do Serviço Nacional de Saúde têm listas definidas de pacientes, e, assim, podem calcular taxas. Mesmo assim, somente médicos entusiasmados mantêm registros de cada encontro com seus pacientes e compilam listas de diagnósticos das condições de que sofrem seus pacientes.

Terceiro ponto, o numerador é incerto porque são colhidos por inúmeros médicos espalhados por incontáveis consultórios e clínicas e variam enormente em qualidade. Em um extremo há os prontuários meticulosamente detalhados contendo uma história médica de vida e no outro são cartões com somente o nome do paciente e a data do atendimento. $\mathrm{O}$ conhecimento e as atitudes individuais dos médicos modificam a sua percepção a respeito das doenças, interferindo nas suas decisões diagnósticas, especialmente no que diz respeito aos distúrbios emocionais e de comportamento.

Outro problema bastante freqüente na administração de um sistema de informação de demanda ambulatorial é a questão da classificação a ser usada. Mesmo nos países desenvolvidos, persiste o problema de se analisar os dados advindos da assistência ambulatorial e o reconhecimento da futilidade de se tentar estabelecer rótulos diagnósticos precisos para condições mal definidas ou incompletamente diagnosticadas.

Os serviços médicos de empresa oferecem condições ideais para a obtenção de dados sobre morbidade, pois se trata de uma população finita, cujas alterações de saúde são quase que totalmente conhecidas dos Médicos do Trabalho, alterações essas que podem ser registradas e seguidas pelo tempo que seja desejado.

Nos termos da lei, cabe ao empregador comunicar ao INPS todo acidente que ocorra, tanto aqueles de simples tratamento médico (quando o trabalhador acidentado se afasta do trabalho por poucos dias, voltando a ele inteiramente curado da lesão sofrida) como aqueles de maior gravidade (acidentes que 
impliquem em maior número de dias de trabalho perdidos ou em lesões que levem a perdas anatômicas e/ou funcionais), através de um documento de comunicação à Previdência Social que é a Comunicação de Acidente do Trabalho - CAT.

Na prática, no entanto, um número elevado de CATs deixa de ser elaborado pelo empregador. Quando da penúltima revisão das leis que regem o acidente do trabalho, cabia ao empregador pagar a diária do dia do acidente, cabendo ao INPS o pagamento dos dias imediatos. Com isso o empregador tinha o maior interesse em que fosse emitida uma CAT, pois isso desobrigava-o de pagamentos por dias perdidos a partir do dia em que o acidente ocorreu.

Em 1976 o INPS - afogado em meio a milhares de CATs e dispensano elevada quantia para o pagamento dos dias perdidos - passou a obrigar o empregador a pagar as diárias dos 15 primeiros dias de afastamento do trabalho por motivo de acidente. Porém, a grande maioria dos acidentes do trabalho é de menor gravidade, implicando no afastamento do trabalho por poucos dias. Em face desse dispositivo legal, nesses casos de menor gravidade não é feita a comunicação ao INPS do ocorrido, sendo o acidentado tratado na própria empresa. Com isso, ficou a Previdência Social sem a informação de um elevado número de acidentes que não lhe são comunicados.

Os registros especiais de doenças, por sua vez, são extremamnte úteis na obtenção de coeficientes de incidência e prevalência, medidas de prognóstico baseadas em tábuas de vida e, principalmente, a tendência da incidência, permitindo que a ocorrência seja examinada independentemente das mudanças na terapêutica, o que pode confundir as tendências de mortalidade.

Uma doença, para propósitos de registro, não pode ser considerada independentemente da pessoa que é vítima dela. Assim, um registro no deve ser confundido com notificação. As doenças infecciosas devem ser notificadas às autoridades médicas a fim de que certos procedimentos de saúde pública possam ser postos em ação. Uma vez terminado o surto, a identificação do indivíduo que tinha a doença deixa de ser importante. Ele se torna "um caso" e não há necessidade de manter um registro permanente das pessoas que tiveram a doença.

Porém, os registros especiais de doenças são extremamente caros para a sua operação e requerem longa manutenção para que se tenha informaçõs úteis, além de se restringirem a uma única doença.

Finalmente pode-se dizer que nos países onde a população não tem acesso fácil aos serviços de saúde, as informações provenientes das fontes rotineiras dão conhecimento da morbidade de apenas uma parte dessa população, ignorando um importante segmento, geralmente o mais pobre, o tais necessitado e aquele que realmente deve ser o alvo das políticas e programas de saúde, principalmente em atenção primária.

Dessa forma é necessário que se lance mão de outros modos de conhecer essa necessidade e, os levantamentos domiciliares dão a oportunidade de olhar 
para todos e encontrar não somente aquelas pessoas que estão no sistema de saúde mas, aquelas que não estão, e saber porque não estão. É provável que as características e problemas de saúde dos que não procuram ou dos que não recebem atendimento, sejam diferentes dos usuários dos serviços de saúde.

Os inquéritos domiciliares são a única fonte que permite que se calcule coeficientes pois o denominador é conhecido, além de concentrarem no indivíduo entrevistado todas as informações a respeito da morbidade e da utilização dos recursos de saúde que teriam de ser coletadas em várioslugares. No entanto, essa fonte de morbidade apresenta algumas dificuldades que a Prof. Luana, com a sua experiência no assunto, já apresentou.

Se por um lado as mudanças epidemiológicas tornaram os dados de mortalidade representativos apenas da "ponta do iceberg", novas tecnologia e metodologia, como os estudos de causas múltiplas, vêm resgatá-los e mostrar que esses dados sempre terão o seu lugar na análise da situação de saúde da população, a despeito de todos os seus defeitos com relação ao preenchimento e a confiabilidade variável.

Apesar disso, essa fonte ainda apresenta problemas como o fato de a grande maioria das pessoas doentes poder ser curada, e haver um longo período entre o aparecimento da doença e a morte. Foi-se o tempo em que a manifestação de uma doença infecciosa aguda era seguida de morte dentro de 24 horas, fazendo com que a mortalidade fosse uma medida direta, confiável, oportuna e acurada da expansão de uma epidemia incontrolável, tornando, dessa forma, as estatísticas de morbidade a medida mais sensível e oportuna das doenças.

\section{Referência Bibliográfica}

ESCRIVÃO Jr., A. As práticas de controle das doenças transmissíveis: a questão da hepatite por virus no Estado de São Paulo. São Paulo, 1985 [Dissertação de Mestrado - Faculdade de Medicina da USP]. 